\title{
Probabilistic Analysis of the Hard Rock Disintegration Process
}

K. Frydrýšek

This paper focuses on a numerical analysis of the hard rock (ore) disintegration process. The bit moves and sinks into the hard rock (mechanical contact with friction between the ore and the cutting bit) and subsequently disintegrates it. The disintegration (i.e. the stress-strain relationship, contact forces, reaction forces and fracture of the ore) is solved via the FEM (MSC.Marc/Mentat software) and SBRA (Simulation-Based Reliability Assessment) method (Monte Carlo simulations, Anthill and Mathcad software). The ore is disintegrated by deactivating the finite elements which satisfy the fracture condition. The material of the ore (i.e. yield stress, fracture limit, Young's modulus and Poisson's ratio), is given by bounded histograms (i.e. stochastic inputs which better describe reality). The results (reaction forces in the cutting bit) are also of stochastic quantity and they are compared with experimental measurements. Application of the SBRA method in this area is a modern and innovative trend in mechanics. However, it takes a long time to solve this problem (due to material and structural nonlinearities, the large number of elements, many iteration steps and many Monte Carlo simulations). Parallel computers were therefore used to handle the large computational needs of this problem.

Keywords: Hard rock (ore), cutting bit, disintegration process, FEM, probability, SBRA method, parallel computing.

\section{Introduction}

Scientific and technical developments (in all areas of world-wide industry) are affected by the growing demand for basic raw materials and energy. The provision of sufficient quantities of raw materials and energy for the processing industry is the main limiting factor of further development.

It is therefore very important to understand the ore disintegration process, including an analysis of the bit (i.e. excavation tool) used in mining operations. The main focus is on modeling the mechanical contact between the bit and the ore, see Fig. 1.

\section{Finite element model of the ore disintegration process}

FEM (i.e. MSC.Marc/Mentat 2005r3 and 2008r1 software) was used in modeling the ore disintegration process. Figure 2 shows the basic scheme (plain strain formulation, mechani-

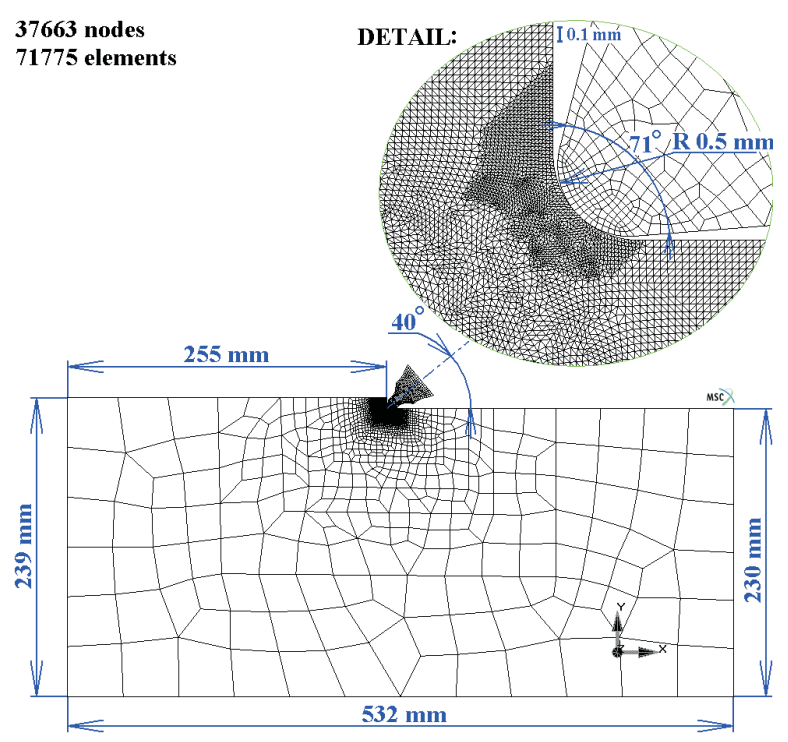

Fig. 2: Geometry of 2D FE model, boundary conditions and details

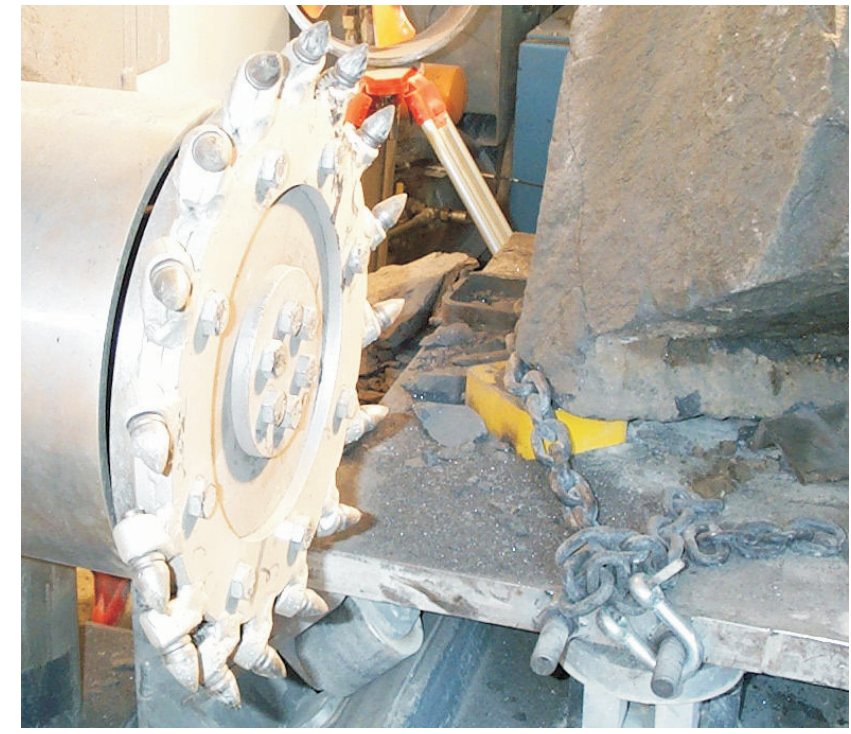

Fig. 1: A typical example of mechanical interaction between bits and hard rock (example of the ore disintegration process)

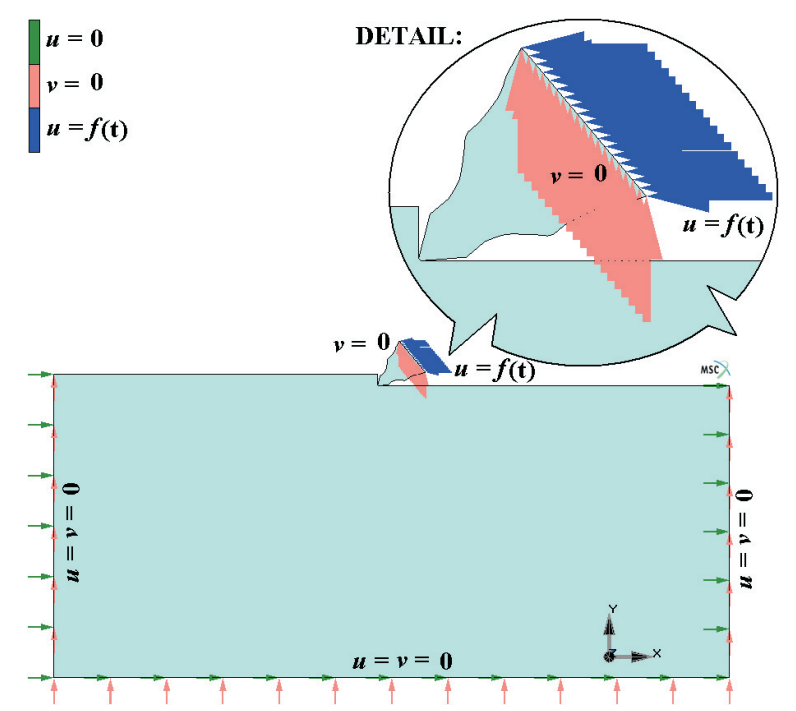


Sintered Carbide $(E=600000 \mathrm{MPa}, \mu=0.22)$ - constant values Steel $(E=210000 \mathrm{MPa}, \mu=0.31)$ - constant values

Ore ( $E, \mu, \mathbf{R}_{\mathrm{p}}, \mathbf{R}_{\mathrm{m}}$ are given by bounded histograms) - stochastic values

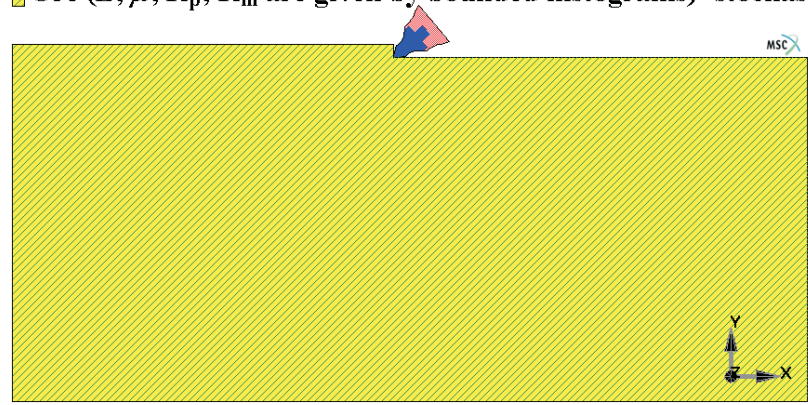

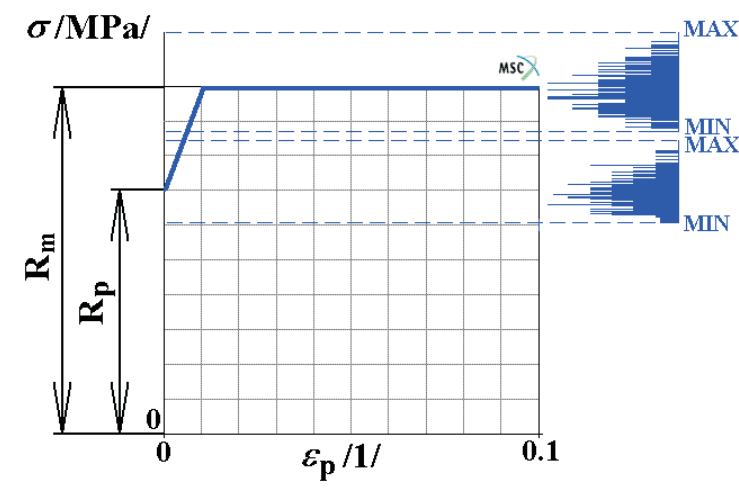

Fig. 3: Material properties - whole model and material of the ore (stress $\sigma$ vs. plastic strain $\varepsilon_{\mathrm{p}}$ )

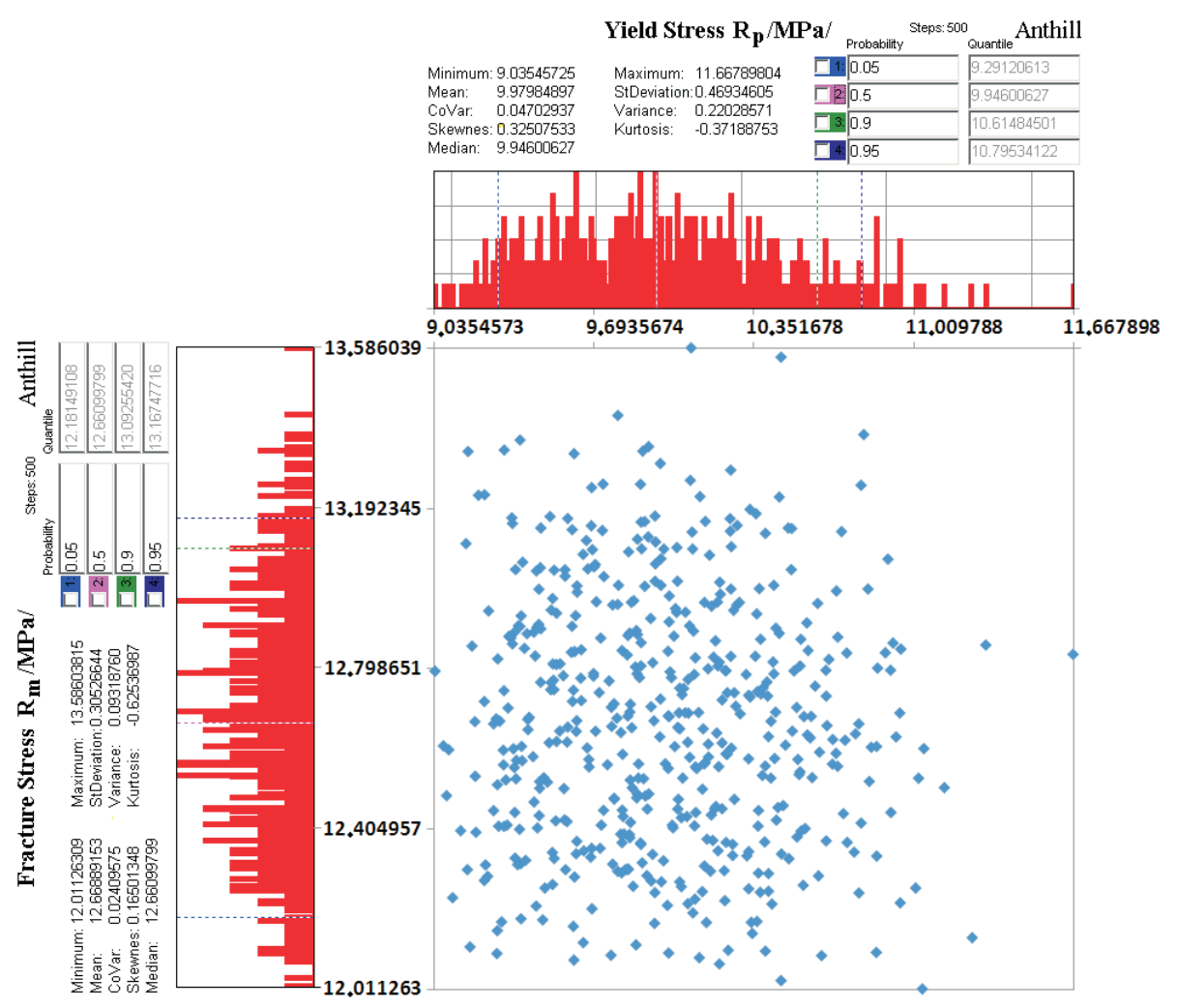

Fig. 4: Stochastic inputs for the material of the ore (histograms for yield stress and fracture stress, results of Anthill software)

cal contact with friction between the bit and platinum ore, boundary conditions, etc.).

Fig. 2 shows that the bit moves into the ore with the prescribed time dependent function $u=f(t)$, and subsequently disintegrates it. When the bit moves into the ore (i.e. a mechanical contact occurs between the bit and the ore) the stresses $\sigma_{\mathrm{HMH}}$ (i.e. the equivalent von Mises stresses) in the ore increase. When the situation $\sigma_{\mathrm{HMH}}>R_{\mathrm{m}}$ occurs (i.e. the equivalent stress is greater than the fracture limit) in some elements of the ore, then these elements break off (i.e. these elements are dead). Hence, a part of the ore disintegrates. In MSC.Marc/Mentat software, this is done by deactivating the elements that satisfy the condition $\sigma_{\mathrm{HMH}}>R_{\mathrm{m}}$. This deacti- vation of the elements was performed in every $5^{\text {th }}$ step of the solution.

For further information see references [1] and [2].

\section{Probabilistic inputs - SBRA (Simulation-Based Reliability Assessment) method}

A deterministic approach (i.e. all types of loading, dimensions and material parameters etc. are constant) provides an older but simple way to simulate mechanical systems. However, a deterministic approach cannot truly include the variability of all inputs, because nature and the world are stochastic. Simulations of the ore disintegration process via a 


\begin{tabular}{|c|c|c|c|c|}
\hline \multirow{2}{*}{ Variable: $\mathrm{E}$} & \multirow{2}{*}{$\nabla$} & \multirow[t]{2}{*}{ ГRecalculate } & \multirow{2}{*}{$\begin{array}{l}\text { Г Discrete Steps: } 500 \\
\text { Probability }\end{array}$} & \multirow{2}{*}{ Auantile } \\
\hline & & & & \\
\hline Minimum: 16095.0000 & Maximum: & 211 & 0.00000000 & 16093.29963000 \\
\hline Mean: $\quad 18543.4423500[$ & StDeviation & $932.20905260-$ & 2:0.00000000 & 16093.29963000 \\
\hline $\begin{array}{l}\text { Covar: } \quad 0.05027163 \\
\text { Skewnes: }-0.03568297\end{array}$ & $\begin{array}{l}\text { Variance: } \\
\text { Kurtosis: }\end{array}$ & $\begin{array}{l}869013.717700[ \\
-0.30033088\end{array}$ & 0.00000000 & 16093.29963000 \\
\hline Median: 18513.8367400[ & & & 0.00000000 & $\longdiv { 1 6 0 9 3 . 2 9 9 6 3 0 0 0 }$ \\
\hline
\end{tabular}

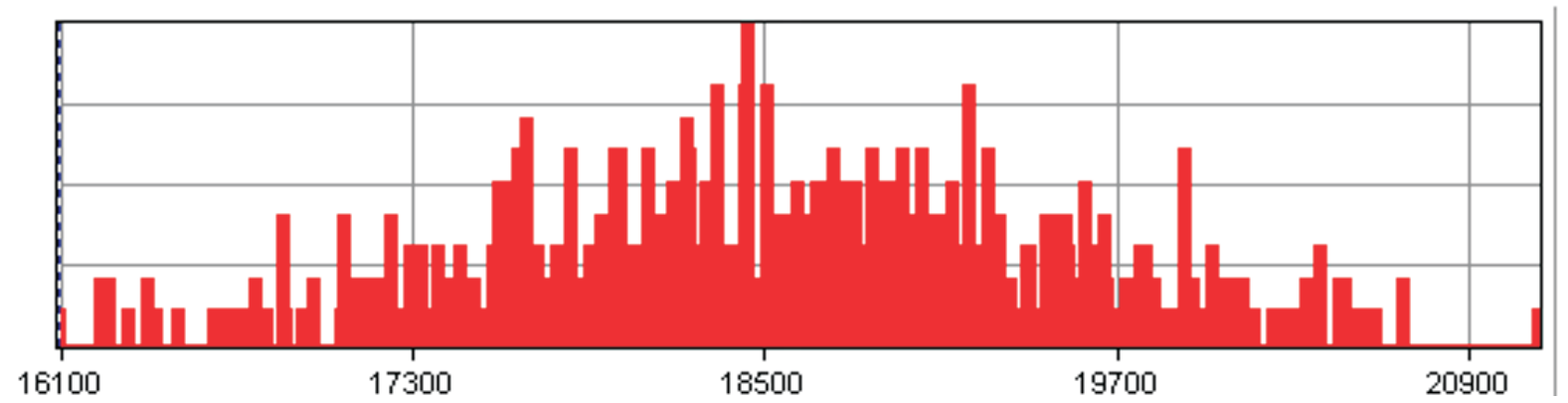

Fig. 5: Stochastic inputs for the material of the ore (histogram of Young's modulus, results of Anthill software)

\begin{tabular}{|c|c|c|c|c|}
\hline \multirow[t]{2}{*}{ Variable: mi } & \multirow[t]{2}{*}{$\nabla$} & \multirow[t]{2}{*}{$\Gamma$ Recalculate } & screte Steps:500 & A \\
\hline & & & & \\
\hline Minimum: 0.18019767 & Maximum: & 0.21990847 & 0.00000000 & 0.18018718 \\
\hline 0.20006540 & StDeviation & 0.01129807 & 0.00000000 & 0.18018718 \\
\hline Covar: $\quad 0.05647186$ & $\begin{array}{l}\text { Variance: } \\
\text { Kurtacic. }\end{array}$ & $\begin{array}{l}0.00012765 \\
-120045257\end{array}$ & 0.00000000 & 0.18018718 \\
\hline $\begin{array}{l}\text { Skewnes: } 0.03696437 \\
\text { Median: } \quad 0.19936996\end{array}$ & Kurtosis: & & 0.00000000 & 0.18018718 \\
\hline
\end{tabular}

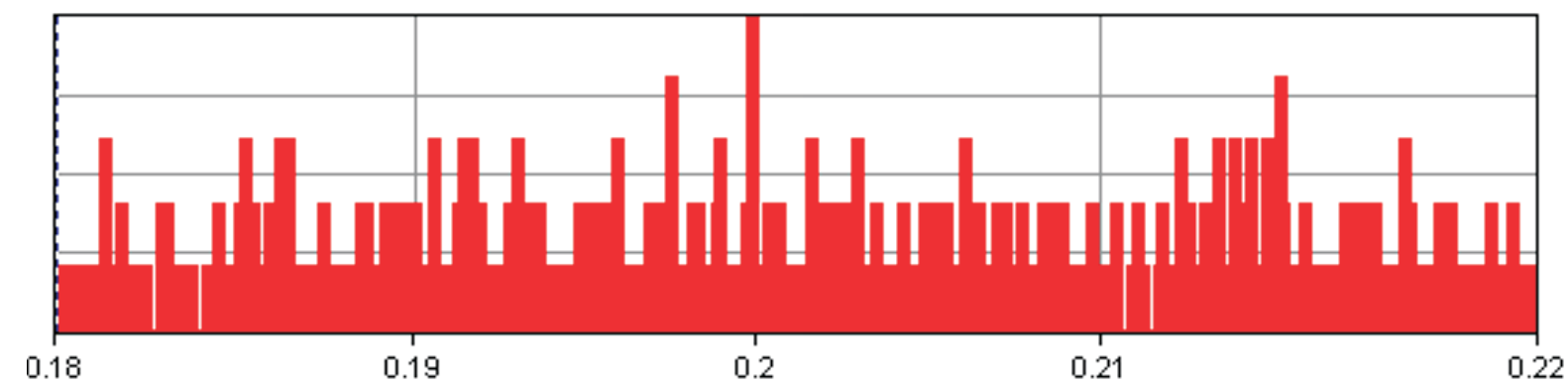

Fig.6. Stochastic inputs for the material of the ore (histogram of Poisson's ratio, results of Anthill software)

deterministic approach are shown in [1] and [2]. However, this problem is also solved via probabilistic approaches which are based on statistics.

Let us consider the "Simulation-Based Reliability Assessment” (SBRA) Method, a probabilistic approach, in which all inputs are given by bounded histograms. Bounded histograms include the real variability of the inputs. Application of the SBRA method (based on Monte Carlo simulations) is a modern and innovative trend in mechanics, see for example [3] to [5].

The material properties (i.e. isotropic and homogeneous materials) of the whole system are described in Fig. 3, where $E$ is Young's modulus of elasticity and $\mu$ is Poisson's ratio.
The bit is made of sintered carbide (sharp edge) and steel. The ore material is elasto-plastic with yield limit $R_{\mathrm{p}}=9.946_{-0.911}^{+1.722}$ and fracture limit $R_{\mathrm{m}}=12.661_{-0.650}^{+0.925}$, which are given by bounded histograms see Figs. 3 and 4 .

The elastic properties of the ore are described by Hooke's law in the histograms

$$
\left.E=18513.8_{-2418.8}^{+2608.8} \mathrm{MP} \text { and } \mu=0.199_{-0.019}^{+0.021}\right),
$$

see Figs. 5 and 6.

Applications of the SBRA method in combination with FEM and subsequent evaluation of the results are shown 


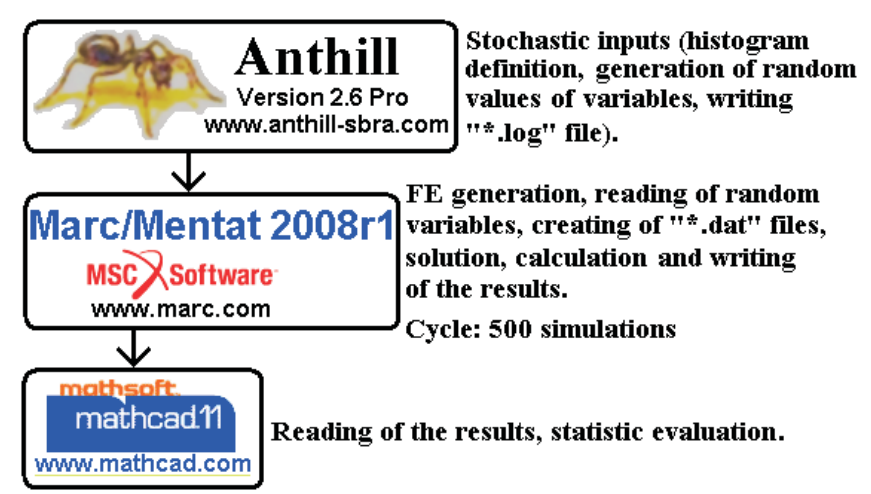

Fig. 7: Computational procedure - application of the SBRA method (solution of the ore disintegration process)

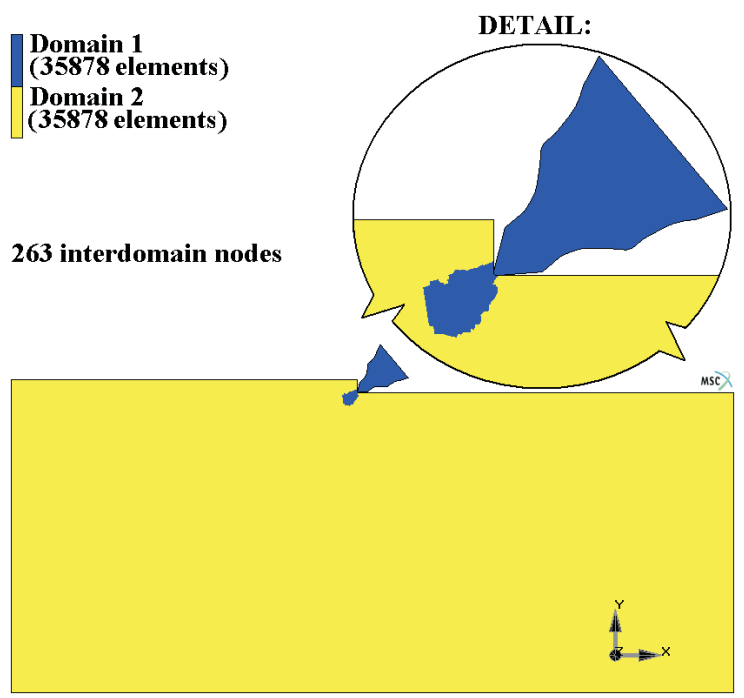

Fig. 8. Domain Decomposition Method Used for Application of 2 CPU and 4 CPU (i.e. Ways of Performing one Monte Carlo Simulation)

Table 1: Parallel computers used in this study (date: August-September 2008)

\begin{tabular}{|c|c|c|c|c|c|}
\hline $\begin{array}{c}\text { Computer } \\
\text { name }\end{array}$ & Computer description & Software & No. of CPU & $\begin{array}{l}\text { No. of MC } \\
\text { simulations }\end{array}$ & $\begin{array}{c}\text { Wall time } \\
\text { (hours) }\end{array}$ \\
\hline Alfa: & $\begin{array}{c}\text { Linux OS, } 8 \text { nodes. } \\
\text { Node configuration: 2x CPU AMD } \\
\text { Opteron } 250 \text { (frequency 2.4 GHz, } 1 \mathrm{MB} \\
12 \text { cache) with } 4 \text { GB RAM } \\
\text { (400MHz DDR) }\end{array}$ & MSC.Marc/Mentat & 16 & 312 & 70.395 \\
\hline Opteron: & $\begin{array}{l}\text { Linux OS, } 1 \text { nodes. } \\
\text { Node configuration: 2x CPU AMD } \\
\text { Opteron } 248 \text { (frequency } 2.2 \mathrm{GHz} \text { ) } \\
\text { with } 8 \text { GB RAM }\end{array}$ & MSC.Marc/Mentat & 2 & 28 & 54.6 \\
\hline Quad: & $\begin{array}{c}\text { Linux OS, } 4 \text { nodes. } \\
\text { Node configuration: 1x CPU AMD } \\
\text { Opteron } 848 \text { (frequency } 2.2 \mathrm{GHz} \text { ) with } 4 \\
\text { GB RAM }\end{array}$ & MSC.Marc/Mentat & 4 & 86 & 69.015 \\
\hline Pca632d: & $\begin{array}{l}\text { MS Windows XP professional } 64 \text { bit OS, } \\
4 \text { nodes. } \\
\text { Configuration: Intel core } 2 \text { quad } \\
\text { CPU q9300 (frequency } 2.5 \mathrm{GHz} \text { ) } \\
\text { with } 8 \text { GB RAM }\end{array}$ & $\begin{array}{l}\text { MSC.Marc/Mentat, } \\
\text { Anthill, } \\
\text { Mathcad }\end{array}$ & 4 & 74 & 68.82 \\
\hline & & & $\sum 26$ & $\sum 500$ & $\sum_{\text {cca }} 70.4$ \\
\hline
\end{tabular}

in Fig. 7. Anthill, MSC.Marc/Mentat and Mathcad software were used.

\section{Solution - SBRA method in combination with FEM}

Because of the material non-linearities, the mechanical contacts with friction, the large number of elements many steps, and the choice of 500 Monte Carlo simulations, four parallel computers were used to handle the large omputational requirements for this problem, see Table 1.

The Domain Decomposition Method (i.e. application of parallel computers) was used, see Fig. 8.

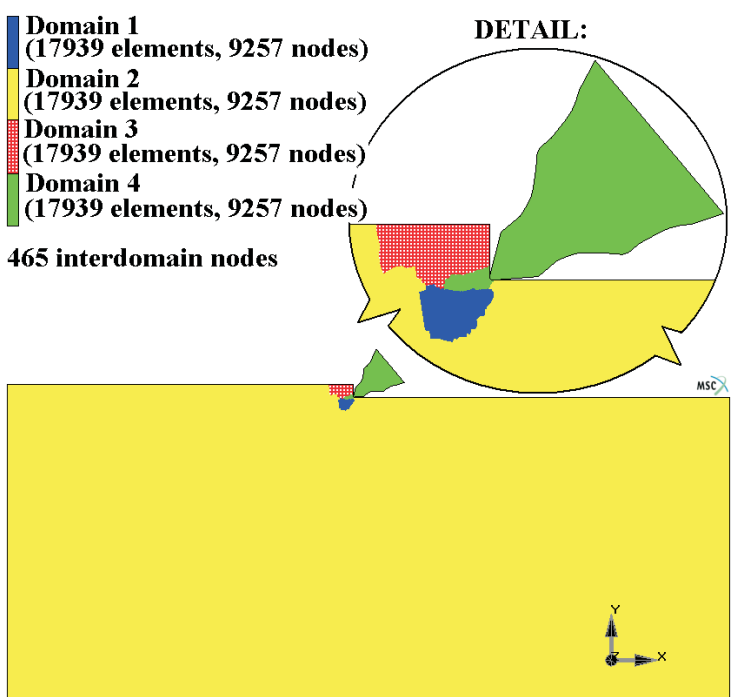


The whole solution time for the non-linear solution (i.e. 1.04 s) was divided into 370 steps of variable length. The Full Newton-Raphson method was used for solving the non-linear problem.

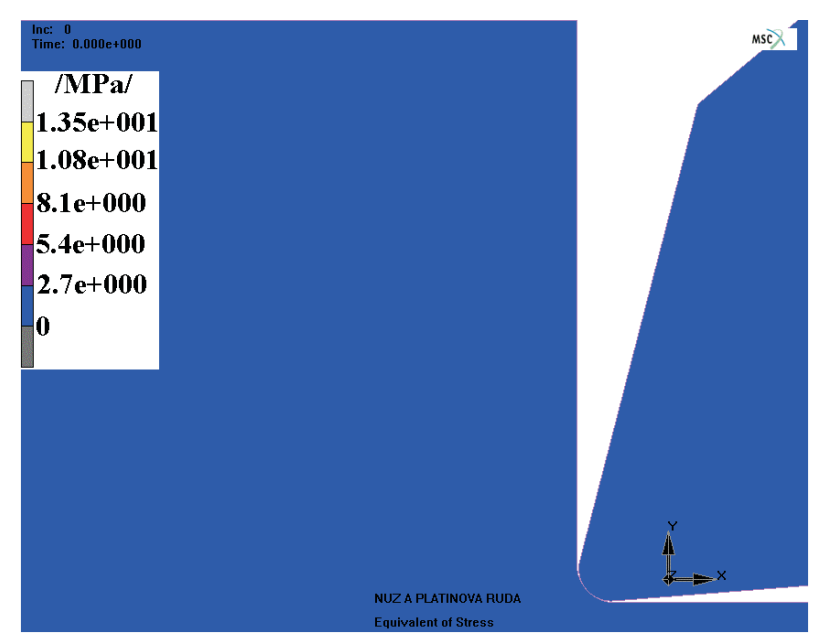

Fig. 9: $t=0 \mathrm{~s}$ (FEM results, start of the solution)

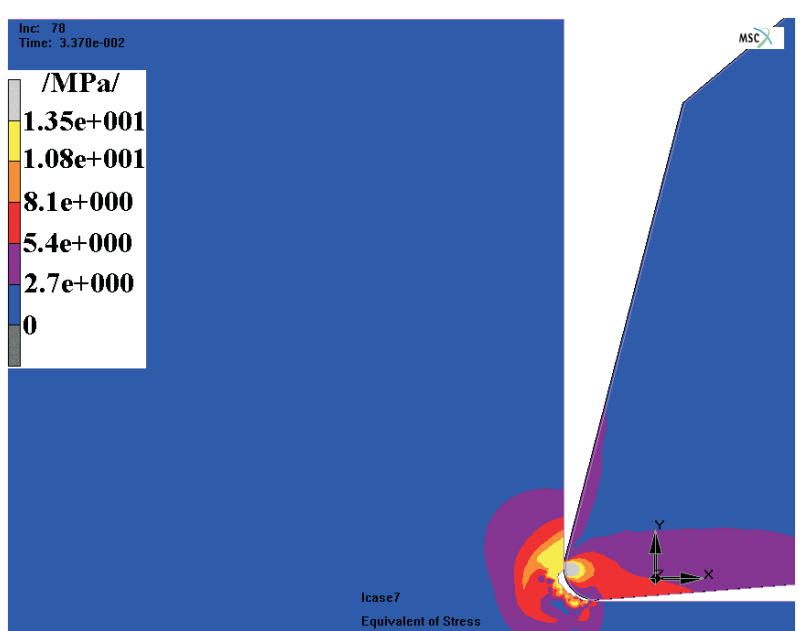

Fig. 10: $t=3.37 \times 10^{-2} \mathrm{~s}(\mathrm{FEM}$ results)

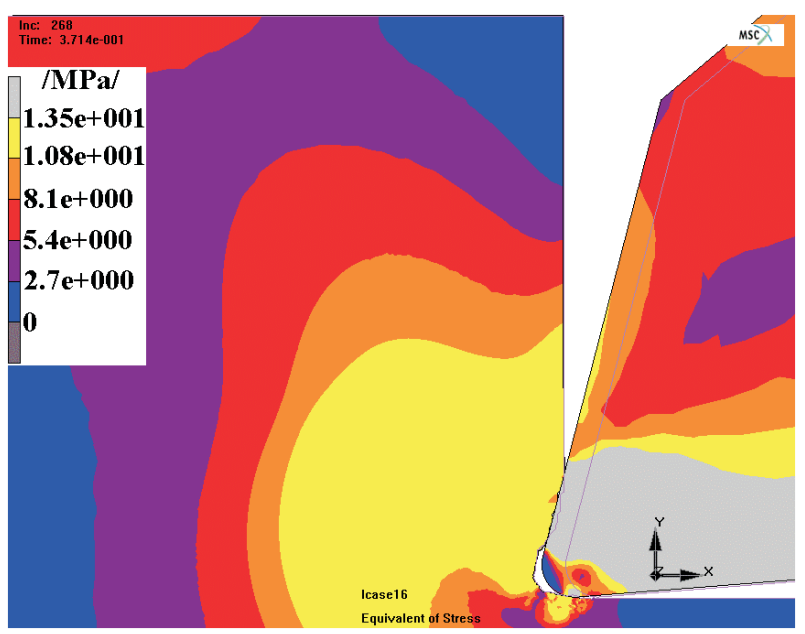

Fig. 11: $t=3.714 \times 10^{-1} \mathrm{~s}($ FEM results)
Table 1 shows that the solution of 500 Monte Carlo simulations (calculated simultaneously on four different parallel computers) takes cca 70.4 hours.

\section{Results - stochastic evaluation}

Figs. 9 to 14 show the equivalent stress (i.e. $\sigma_{\mathrm{HMH}}$ distributions) at some selected time $t$ of the solution calculated for one of 500 Monte Carlo simulations (i.e. for one situation when the material of the ore is described by values $R_{\mathrm{p}}=12 \mathrm{MPa}$, $R_{\mathrm{m}}=13.5 \mathrm{MPa}, E=20000 \mathrm{MPa}$ and $\mu=0.2$ ). The movement of the bit and also the subsequent disintegration of the ore caused by the cutting are shown.

From the FEM results, we can calculate the reaction forces $R_{X}, R_{Y}$ and the total reaction force $R=\sqrt{R_{X}^{2}+R_{Y}^{2}}$ which acts in the bit, see Figs. 15 and 16. Figure 16 is calculated for one simulation (i.e. for the situation when the material of the ore is described by values $R_{\mathrm{p}}=12 \mathrm{MPa}, R_{\mathrm{m}}=13.5 \mathrm{MPa}$, $E=20000 \mathrm{MPa}$ and $\mu=0.2$ ).

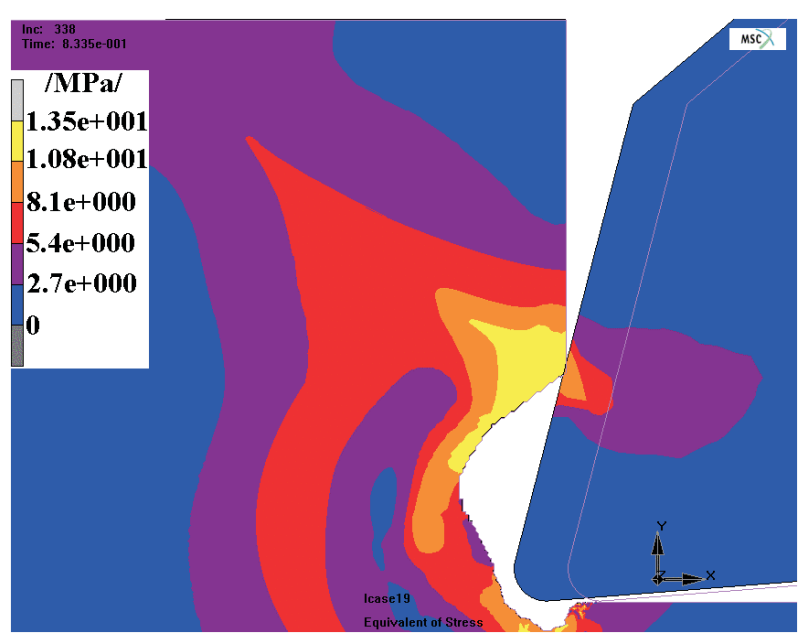

Fig. 12: $t=8.335 \times 10^{-1} \mathrm{~s}(\mathrm{FEM}$ results)

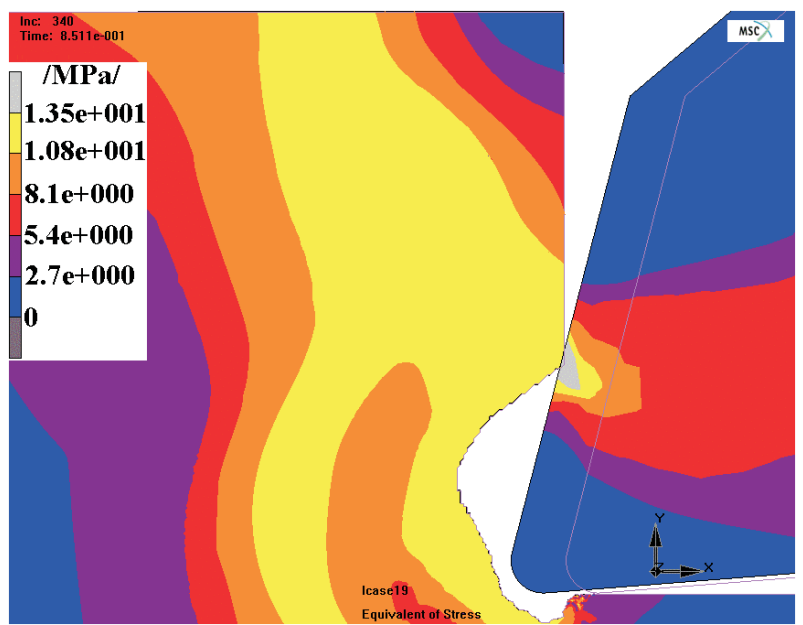

Fig. 13: $t=0.8511 \mathrm{~s}$ (FEM results) 


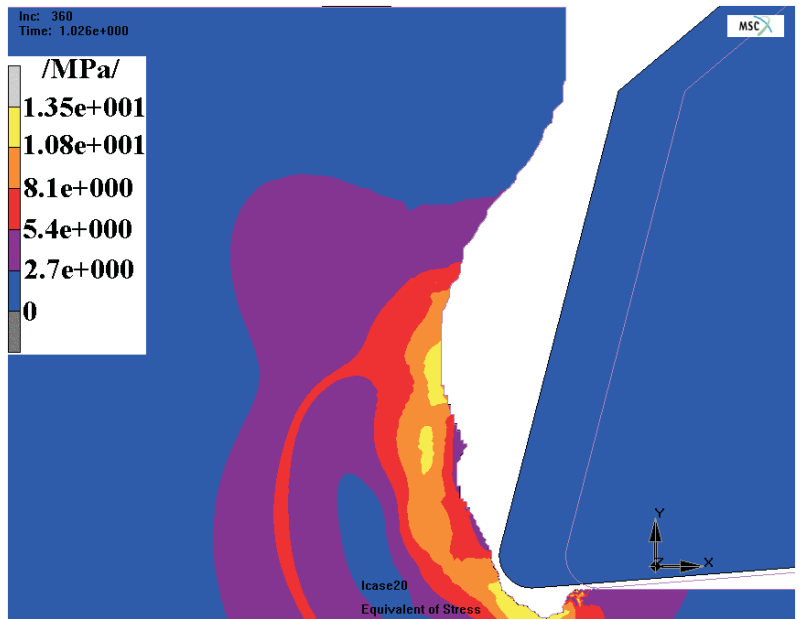

Fig. 14: $t=1.026 \mathrm{~s}$ (FEM results)

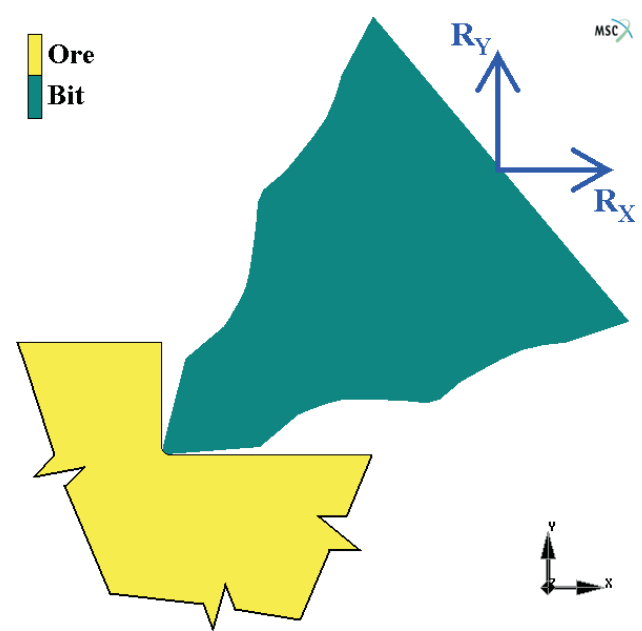

Fig.15. Reaction forces in the bit

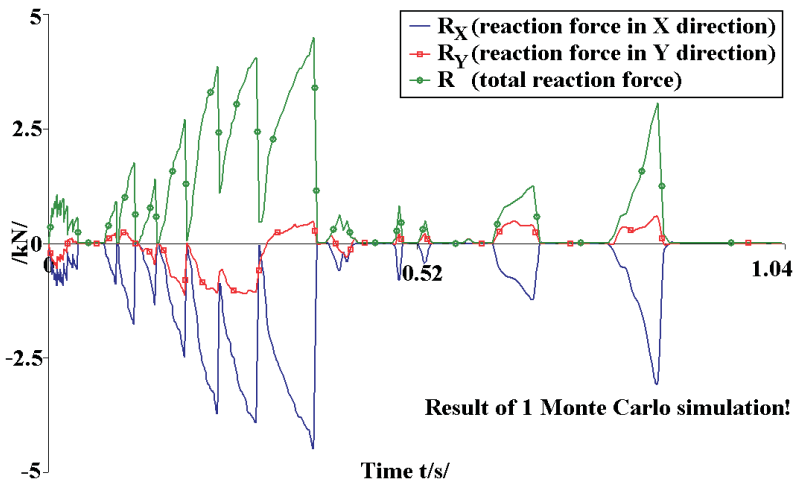

Fig.16. Reaction forces in the bit (FEM results)

A distribution of the total reaction forces acquired from 500 simulations is shown in Fig. 17.

The maximum total reaction force (acquired from 500 Monte Carlo simulation) is given by the histogram $R_{\mathrm{MAX}}{ }_{\text {SBRA,FEM }}=5068_{-984}^{+1098} \mathrm{~N}$, see Fig. 18 .

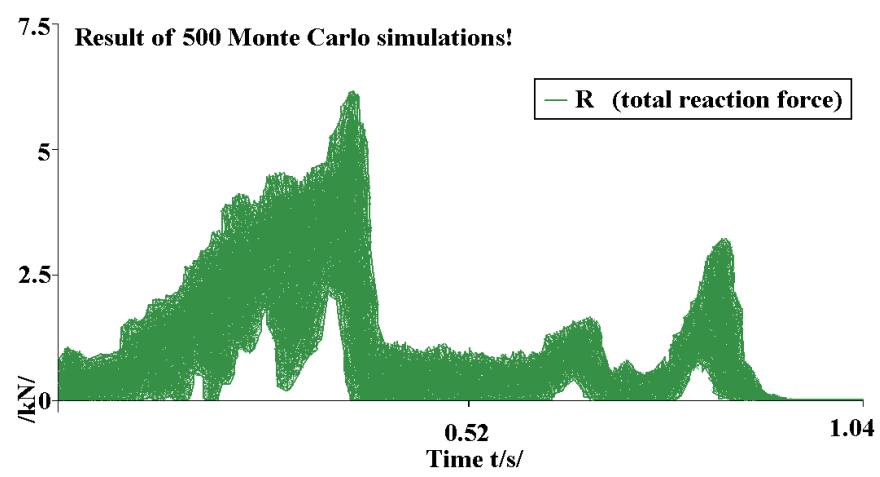

Fig. 17: Total reaction forces in the bit (SBRA-FEM results)

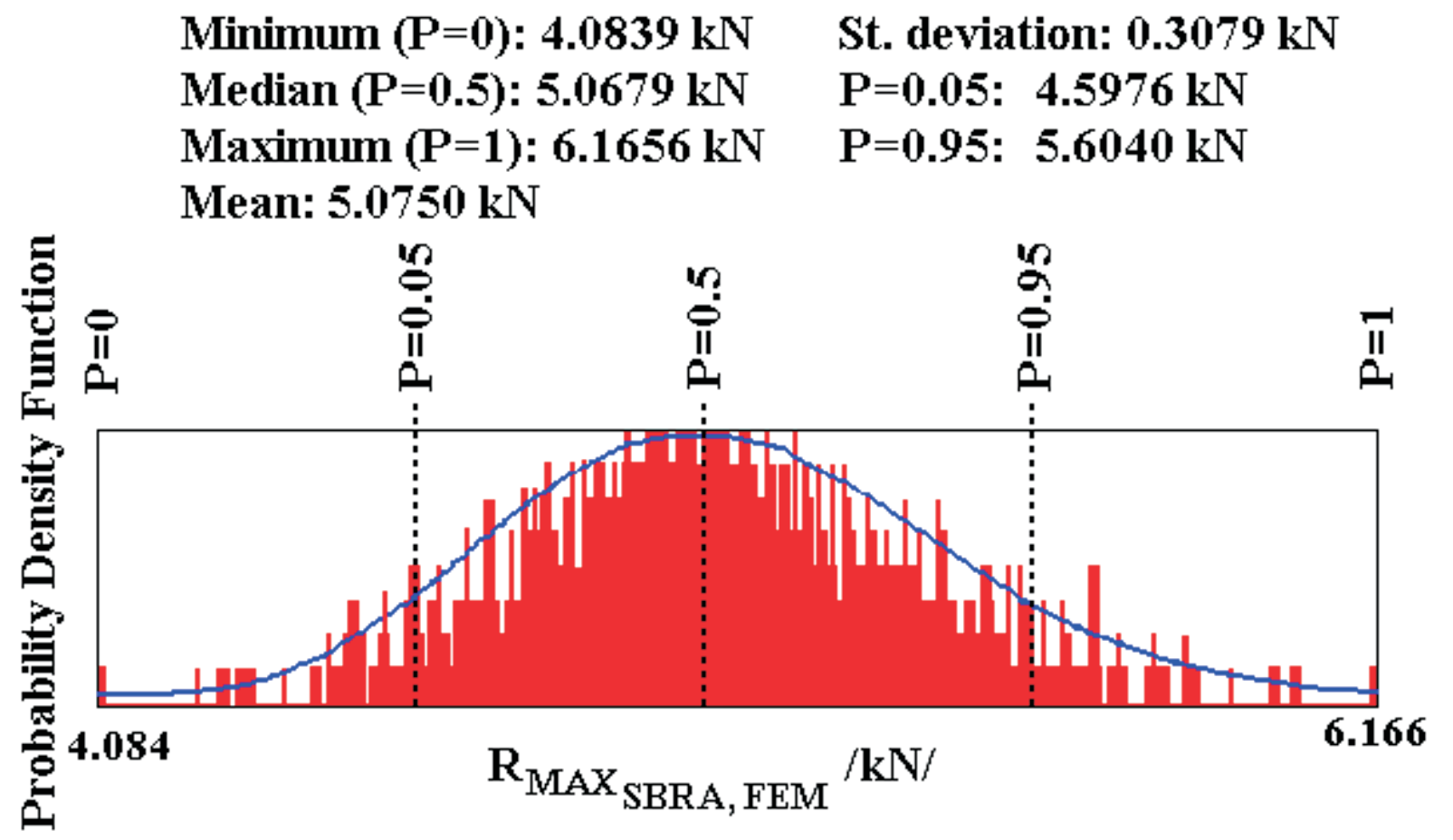

Fig. 18: Maximum total reaction forces in the bit (SBRA-FEM results of 500 Monte Carlo simulations), and an evaluation 


\section{Comparison between stochastic results and experimental measurements}

The calculated maximum forces (i.e. SBRA-FEM solutions, see Fig. 18) can be compared with the experimental measurements (i.e. compared with a part of Fig. 19), see also [1] and [2].

The evaluation of one force measurement (Fig. 19) shows that the maximum force is $R_{\mathrm{MAX}}=5280 \mathrm{~N}$. Hence, the relative error calculated for the acquired median value $R_{\mathrm{MAX}_{\mathrm{SBRA}, \mathrm{FEM}-\mathrm{MED}}}=5068 \mathrm{~N}$, see Fig. 18, is:

$$
\Delta_{R_{\mathrm{MAX}}}=\frac{R_{\mathrm{MAX}_{\mathrm{EXP}}}-R_{\mathrm{MAX}_{\mathrm{SBRA}, \mathrm{FEM}-\mathrm{MED}}}}{0.01 \times R_{\mathrm{MAX}_{\mathrm{EXP}}}}=4.02 \% .
$$

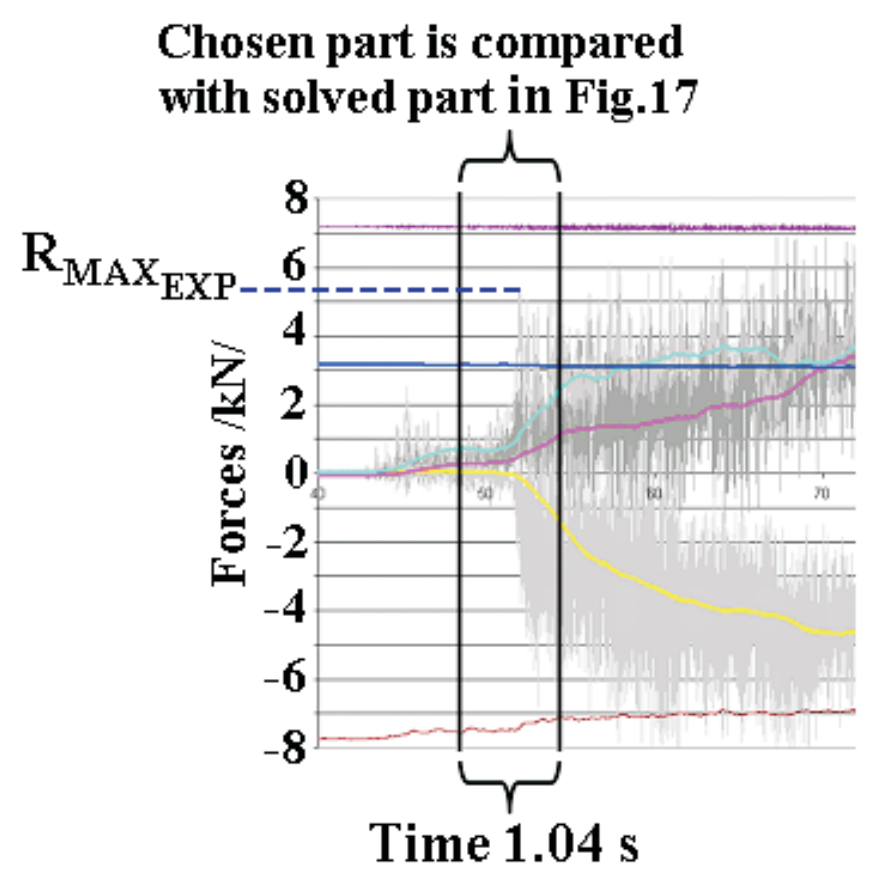

Fig. 19: Experimental measurement, compared with the SBRA-FEM

The error of $4.02 \%$ is acceptable. However, the experimental results also have large variability due to the anisotropic and stochastic properties of the material and due to the large variability of the reaction forces, see Fig. 19.

\section{Conclusions}

This paper combines the SBRA (Simulation Based Reliability Assessment) method and FEM as a suitable tool for simulating the hard rock (ore) disintegration process. All basic factors have been explained (2D boundary conditions, material nonlinearities, mechanical contacts and friction between the cutting bit and the ore, the methodology for deactivating the finite elements during the ore disintegration process, application of parallel computers). The use of finite element deactivation during the ore disintegration process (as a way of expanding the crack) is a modern and innovative way of solving problems of this type.

The error of the SBRA-FEM results (i.e. in comparison with the experiments) is acceptable. Hence, SBRA and FEM can be a useful tool for simulating the ore disintegration process.

Because the real material of the ore (i.e. yield limit, fracture limit, Young's modulus, Poisson's ratio etc.) is very variable, stochastic theory and probability theory were applied (i.e. the SBRA method).

The SBRA method, which is based on Monte Carlo simulations, can include all stochastic inputs and then all results are also of stochastic quantities. However, for better application of the SBRA method (for simulating this large problem in mechanics) it is necessary to use superfast parallel computers. Instead of 500 Monte Carlo simulations (wall time cca 70 hours, as presented in this article), it is necessary to calculate $>10^{4}$ simulations (wall time cca 58 days), or more. Our department will be able to make these calculations when faster parallel computers became available.

All the results presented here were applied for optimizing and redesigning the bit.

In the future, 3D FE models (instead of 2D plane strain formulation), will be applied for greater accuracy.

Other methods for simulating the ore disintegration process are presented in [6] and [7].

\section{Acknowledgment}

This work has been supported by the Czech project FRVŠ 534/2008 F1b.

\section{References}

[1] Frydrýšek, K.: Výpočtová zpráva styku nože a platinové rudy při těžb̌ (Calculation Report on Contact between the Bit and Platinum Ore During Mining), 2007, Czech Republic, 2007, p. 17 (in Czech language).

[2] Frydrýšek, K., Gondek, H.: Finite Element Model of the Ore Disintegration Process, In: Annals of the Faculty of Engineering Hunedoara - Journal of Engineering, Tome VI, Fascicule 1, ISSN 1584-2665, University Politechnica Timisoara, Faculty of Engineering - Hunedoara, Romania, 2008, p. 133-138.

[3] Frydrýšek, K.: Performance-Based Design Applied for a Beam Subjected to Combined Stress, In: Annals of the Faculty of Engineering Hunedoara - Journal of Engineering, Tome VI, Fascicule 2, ISSN 1584-2665, University Politechnica Timisoara, Faculty of Engineering Hunedoara, Romania, 2008, p. 129-134.

[4] Marek, P., Brozzetti, J., Guštar, M., Tikalsky, P.: Probabilistic Assessment of Structures Using Monte Carlo Simulation Background, Exercises and Software, (2 ${ }^{\text {nd }}$ extended edition), ISBN 80-86246-19-1, ITAM CAS, Prague, Czech Republic, 2003, p. 471.

[5] Marek, P., Guštar, M., Anagnos, T.: Simulation-Based Reliability Assessment For Structural Engineers. CRC Press, Boca Raton, USA, ISBN 0-8493-8286-6, 1995, p. 365.

[6] Zubrzycki, J., Jonak, J.: Numeryczno-eksperymentalne badania wplyvu kstaltu powierchni natarcia ostrza na obciaženie 
noža skrawajacego naturalny material kruchy (in Polish language), Lubelskie Towarzystwo Naukowe, Lublin, Poland, 2003, ISBN 83-87833-42-8, p. 90.

[7] Podgórski, J., Jonak, J.: Numeryczne badania procesu skravania skat izotroporych (in Polish language), Lubelskie Towarzystwo Naukowe, Lublin, Poland, 2004,

ISBN 83-87833-53-3, pp. 80.

MSc. Karel Frydrýšek, Ph.D., Ing-Paed IGIP

phone: +420 597324552

e-mail: karel.frydrysek@vsb.cz

Department of Mechanics of Materials

\section{VŠB-TU Ostrava}

Faculty of Mechanical Engineering

17. listopadu 15

70833 Ostrava, Czech Republic 